SEÇão 1

CONCEITUAÇÃO ELEMENTAR 



\section{USO DA ÁGUA DE LASTRO PELOS NAVIOS}

NEWTON NARCISO PEREIRA, HERNANI LUIZ BRINATI

\subsection{CONSIDERAÇÕES PRELIMINARES}

Antes de comentarmos sobre as consequências propriamente ditas do uso da água de lastro em navios mercantes iremos apresentar a origem da necessidade da utilização do lastro em navio. A operação eficiente e segura dos navios sempre exigiu o uso de algum tipo de lastro. Por milênios, embarcações carregaram o lastro continuamente sob a forma de rochas, areia, telhas e muitos outros materiais pesados (NATIONAL RESEARCH COUNCIL, 1996). No início do século 20, as embarcações passaram a utilizar a água de oceanos, rios e lagos como lastro. A água oferece maior flexibilidade que os outros tipos de materiais utilizados neste processo, pois está sempre disponível onde o navio está operando, inclusive durante as viagens. Além disso, evita-se o carregamento demorado de materiais e as instabilidades perigosas para a embarcação, causadas pelo movimento do lastro sólido.

Atualmente, praticamente todas as embarcações marítimas utilizam a água de lastro em suas operações, sendo que esta pode ser armazenada em uma grande variedade de tanques. A complexidade relativa das operações de lastro depende do tamanho, da configuração, das exigências do navio, bem como de seu sistema 
de bombeamento e tubulações. A capacidade de lastro pode variar de dezenas de metros cúbicos para barcos de pesca e lazer, à centenas de milhares de metros cúbicos em grandes navios de carga. Os grandes petroleiros podem carregar até $200.000 \mathrm{~m}^{3}$ de água de lastro, incluindo tanques e porões de carga e as taxas de bombeamento do lastro podem atingir de $15.000 \mathrm{~m}^{3} / \mathrm{h}$ a $20.000 \mathrm{~m}^{3} / \mathrm{h}(\mathrm{NATIO}$ NAL RESEARCH COUNCIL, 1996). Navios graneleiros podem carregar até $120.000 \mathrm{~m}^{3}$ de água de lastro em seus tanques, mantendo a relação de aproximadamente $30 \%$ da capacidade de lastro em função do DWT ${ }^{1}$ (COHEN, 1998). Além disso, mais recentemente, a nova geração de navios de contêineres produzidas pela Maersk, os chamados Triple E, com capacidade de transportar 18.000 TEUS $^{2}$ são capazes de armazenar aproximadamente $60.000 \mathrm{~m}^{3}$ de água de lastro a bordo de seus tanques. Existe uma tendência de nos próximos anos maiores navios de contêineres serem construídos com capacidade de até 21.000 TEUS, transportando maior quantidade de água de lastro.

\subsection{CRITÉRIOS GERAIS DE PROJETO DE NAVIOS}

É importante ressaltar que, como critério básico de projeto, a distribuição dos tanques de lastro deve garantir que em todas as condições de operação sejam consideradas:

a) adequada estabilidade transversal e longitudinal da embarcação;

b) integridade estrutural, evitando que a distribuição de cargas comprometa sua resistência estrutural;

c) a imersão adequada do hélice, de modo que o sistema propulsor opere com eficiência e segurança.

Por outro lado, o planejamento das operações de lastro ou deslastro do navio, concomitantemente com as operações de descarregamento ou carregamento, deve também contemplar os itens (a) e (b).

O comandante do navio prepara o plano de carga, em que se estabelece as quantidades de cargas em cada porão e a sequência de deslatro em função do carregamento do navio.

Outra condição que deve ser observada refere-se ao volume de água de lastro nos tanques. Os volumes contidos nestes tanques variam de acordo com a dura-

1 Dead Weight Tonnage - DWT - Também conhecido como o peso morto do navio, ou seja, que representa a capacidade de carga que um navio é capaz de transportar considerando além da carga o peso dos viveres e consumíveis a bordo do navio.

2 Twinty Feet Equivalent Unit - TEU - é uma medida que refere-se a capacidade de carga de um contêiner. 
ção da viagem. Os tanques de lastro, bem como alguns tanques de combustível e tanques contendo a água fresca para o uso doméstico, que podem estar parcialmente cheios durante a viagem, são usados para controlar o trim ${ }^{3}$ dependendo das exigências de estabilidade do navio. Em geral, busca-se navegar sempre que possível com os tanques completamente cheios ou inteiramente vazios. Quando um tanque não estiver completamente cheio, pode ocorrer o efeito de superfície livre do líquido, que desloca o centro de gravidade do líquido no tanque, podendo assim reduzir a estabilidade transversal do navio.

Enquanto o combustível é consumido durante uma viagem, o calado e o trim do navio mudam. Durante uma viagem longa, milhares de toneladas de combustível são consumidas. Assim, para manter o casco imerso corretamente, é frequentemente necessário colocar lastro adicional à medida que a viagem progride. A capacidade e a posição do lastro durante uma determinada viagem são estabelecidas, considerando a estimativa do combustível que será consumido, condições meteorológicas esperadas, o calado e o trim exigidos para o porto de chegada. Em algumas condições o lastro é despejado durante a entrada no canal do porto, devido às restrições físicas impostas pelo canal de acesso (COHEN, 1998).

Não é incomum navios saírem ou entrarem em um determinado canal de acesso portuário sem o seu calado de projeto e completarem o lastro longe da costa, devido às restrições de entrada e saída. Isso deve-se às características dos navios, bem como, às limitações de canal de acesso portuário, além dos equipamentos utilizados na operação de carga e/ou descarga do navio.

\subsection{PROBLEMAS COM OPERAÇÃO DE LASTRO}

\subsubsection{Perda de estabilidade transversal e longitudinal}

A água de lastro é captada a bordo das embarcações para garantir condições seguras de funcionamento exigidas durante uma determinada viagem. Assim, o lastro e o deslastro do navio buscam garantir que durante todo o tempo de viagem o navio atenda às exigências técnicas para sua operação de maneira segura. O processo de lastreamento é de responsabilidade da tripulação, ou seja, dos oficiais do navio, que conhecem os requisitos necessários para a manutenção apropriada do trim e da estabilidade da embarcação no mar. O comandante do navio é responsável por garantir que todas as operações sejam executadas de maneira segura (NATIONAL RESEARCH COUNCIL, 1996).

3 TRIM: é a inclinação longitudinal do casco do navio. Quando o navio não está alinhando tanto a popa quanto a proa dizemos que ele está com um trim para um dos lados. 
Existem vários relatos de acidentes envolvendo navios durante as operações de lastro. Esta não é uma tarefa fácil e requer um controle apurado do processo, caso contrário pode ocorrer acidentes, semelhantes ao acontecido com o navio MV Cougar Ace no porto de Portland nos Estados Unidos, em 2006. No momento da troca da água de lastro ocorreu uma falha no controle do volume dos tanques, ocasionando o emborcamento do navio, conforme mostrado na Figura 1. Observa-se neste caso que o problema ocorrido estava associado à estabilidade do navio, que foi prejudicada devido à falha ocorrida.

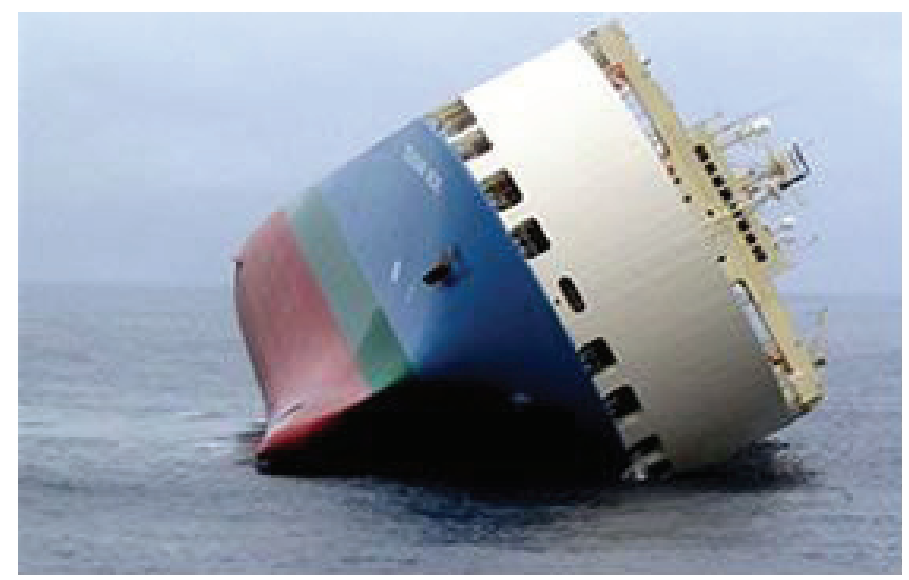

Figura 1 Navio MV Cougar Ace

Crédito da imagem: Kevin Bell - http://www.chesapeakequarterly.net/V08N2/main1/

\subsubsection{Comprometimento da integridade estrutural}

O controle da água de lastro dentro dos tanques dos navios visa garantir a integridade estrutural das embarcações, evitando que a distribuição de cargas comprometa sua resistência estrutural. Qualquer falha neste processo pode resultar na ruptura do casco do navio.

A experiência dos autores resultante de visitas a diversos terminais portuários mostram que em algumas ocasiões é necessário interromper o carregamento do navio e, esperar até que a água de lastro seja descarregada para retomar a operação, pois o sistema de deslastro não é capaz de acompanhar a velocidade do sistema de carregamento.

\subsubsection{Imersão inadequada do hélice}

Quando o navio opera em carga parcial ou em condição de lastro o hélice pode não ficar completamente submerso. Em consequência, quando o hélice está propelindo o navio, ocorra diferença de pressão muito grande entre uma pá que 
está dentro d’água e outra pá que está fora, gerando cavitação, vibração de eixo, ruído, podendo até romper o eixo do propulsor.

Assim, para uma operação eficiente do hélice, exige-se que ele esteja sempre imerso, mesmo em águas rasas. Nos casos em que o peso da praça de máquinas, junto com a carga, não seja suficiente para manter o hélice imerso torna-se necessário o emprego de lastro.

Além disso, se o calado de popa não for suficiente em condições mais severas de mar, o hélice do navio irá acelerar, isto é, aumentam suas rotações por minuto quando emergir da água e retardam quando reentrar na água. Isto pode causar problemas no controle do motor e aumentar o carregamento no seu eixo. Aumentar o calado de popa reduz a tendência do hélice emergir e, reduz-se assim aceleração. Consequentemente, a operação segura do navio sob mau tempo exige a adição de lastro (NATIONAL RESEARCH COUNCIL, 1996).

\subsection{PROJETO DO SISTEMA DE LASTRO}

Há diferentes arranjos para os tanques de lastro. Cada configuração é mais adequada a um determinado tipo de navio em função das suas características operacionais. A Figura 2 mostra os tipos de configuração de tanques mais encontrados em navios de carga.

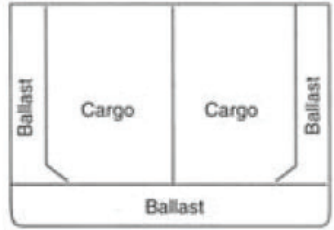

Navio Tanque

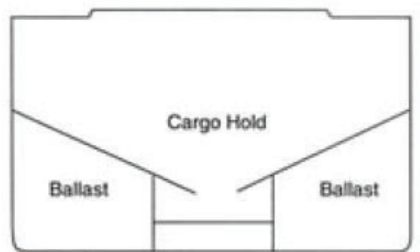

Navio de carga padrão Grandes Lagos classe intermediária

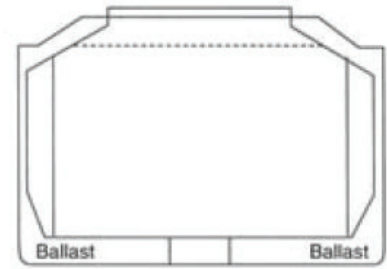

Navio Tanque Panamax

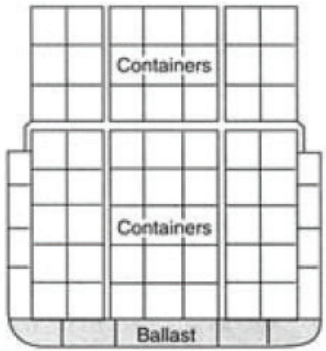

Navio de contêiner

Figura 2 Configurações típicas de tanques de lastro para navios mercantes 
As tubulações são feitas sob medida, de modo que as velocidades de escoamento estejam na faixa de $2,6 \mathrm{~m} / \mathrm{s}$ à $3 \mathrm{~m} / \mathrm{s}$; as bombas de lastro têm capacidade de até $5.000 \mathrm{~m}^{3} / \mathrm{h}$ (NATIONAL RESEARCH COUNCIL, 1996). Não há nenhuma unidade de medida internacional padrão para o lastro; as quantidades são variáveis anotadas em toneladas métricas e ou metros cúbicos. As taxas de bombeamento para diferentes tipos de navio estão apresentadas na.

Obviamente, a capacidade, localização, tipo de bomba e todo detalhamento do sistema de lastro são definidos no projeto de navio. Considerações sobre calado e trim requeridos, limitações de carregamento do casco, e posição vertical exigida do centro de gravidade estabelecem o volume e a posição dos tanques de lastro.

Geralmente, os armadores procuram otimizar a utilização do navio, buscando sempre que possível dispor de carga, tanto na viagem de ida quanto na volta do navio. Entretanto, em muitas viagens o navio a realiza num trecho sem carga, isto é, operando na condição de peso leve. Nesta condição utiliza-se água de lastro como elemento estabilizador do navio.

Tabela 1 Necessidade de lastro e taxas de bombeio

\begin{tabular}{|c|c|c|}
\hline Lastro necessário & Tipos de embarcação & Taxa de bombeamento(m $3 / \mathrm{h})$ \\
\hline Lastro para reposição de carga & Navios de granel seco & $5000-10000$ \\
Lastro necessário em grandes & Navios de minério & 10000 \\
quantidades, essencialmente & Tanquers & $5000-20000$ \\
para retorno de viagens & Navios de gás liquefeito & $5000-10000$ \\
& Petroleiros & $10000-15000$ \\
\hline Lastro para controlde de embarcação & Navio de containeres & $1000-2000$ \\
Lastro necessário na maiorria das & Balsa & $200-500$ \\
condições de carregamento para & Navio de passageiros & $1000-2000$ \\
controle de estabilidade, trim e heel. & Navios Roll-on,roll-off & $200-500$ \\
& Navios de carga geral & $1000-2000$ \\
& Pesqueiros & 50 \\
& Pesqueiros industrias & 500 \\
& Navios militares & $50-100$ \\
\hline Lastro para carregamento e & Navios float-on, float-off & $10000-15000$ \\
Lastro adiquirido na localidade em & Navios militares anfibios de assalto & 5000 \\
grandes volumes e descarregamento & Barca de carregador & 5000 \\
no mesmo local & & $1000-2000$ \\
& & \\
\hline & & \\
\hline
\end{tabular}

Fonte: Adaptado de NATIONAL RESEARCH COUNCIL (1996)

A experiência dos autores mostra que quando o navio está parcialmente carregado, utiliza-se a quantidade mínima de água de lastro necessária para garantir sua segurança até chegar ao próximo porto. $\mathrm{O}$ uso de maior quantidade de lastro 
implica em aumento de calado com consequente aumento de potência e de gastos com combustível, o que geralmente é evitado.

Algumas embarcações controlam o movimento de emborcamento através de tubulações que permitem mover a água de lastro entre os tanques para manter a embarcação dentro de uma tolerância do jogo do vertical (NATIONAL RESEARCH COUNCIL, 1996).

O sistema de lastro é formado por numerosas tubulações, bombas e válvulas ligadas aos tanques de lastro dos navios. Os sistemas podem ser individualizados ou integrados e o controle é realizado na praça de máquinas. As válvulas geralmente são operadas remotamente através de sistemas hidráulicos.

Atualmente, não é incomum encontrar modernos navios graneleiros projetados com sistema de lastro totalmente conectado, tanto para os tanques de asas quanto com os tanques do duplo fundo e costado. Resulta, então, um sistema de drenagem dos tanques, totalmente integrado, eliminando a necessidade da existência de um sistema de tubulação separado para os tanques superiores. Em arranjos convencionais, os tanques do duplo fundo são completamente separados e podem ser acessados apenas através de aberturas dos tanques de carga. Assim, a entrada para inspeção, manutenção ou limpeza é apenas possível quando a área de acesso está próxima ao tanque de carga (JOHENGEN et al., 2005).

A água de lastro é captada a bordo através das caixas de mar conectadas às bombas ou perto de um sistema de alimentação por gravidade. As caixas de mar podem ser posicionadas no fundo do navio ou no costado geralmente em ambos os lados da embarcação.

O carregamento da água lastro e as operações de descarregamento são geralmente controladas de uma estação central de monitoração/controle, em que a água pode ser lançada para fora de um tanque ou bombeada de dentro para fora, ou através da combinação dos métodos, mostrado na Figura 3.
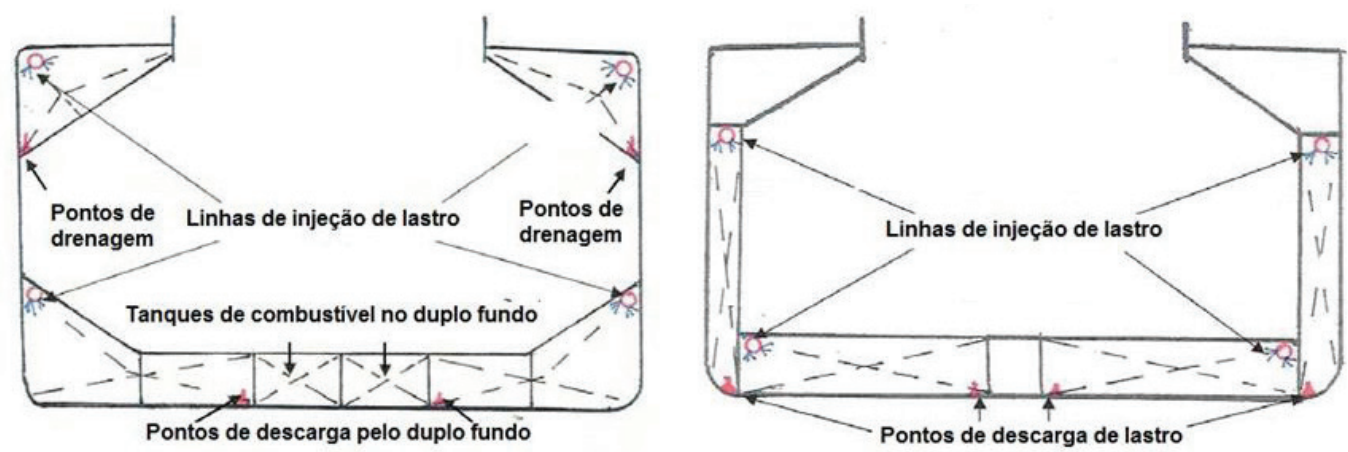

Figura 3 Localização dos pontos de captação de despejo da água de lastro e pontos de captação de despejo da água de lastro

Fonte: Adaptado de Johengen et al. (2005) 
As bombas conseguem remover boa parte da água dos tanques. Em alguns casos o trim de proa do navio pode ser usado para ajudar na remoção do lastro. Embora se utilize destes meios, alguma quantidade de água e de sedimento sempre se acumula no interior dos tanques (BOLCH e HALLEGRAEFF, 1993).

A entrada da caixa de mar é coberta com uma grelha ou uma placa formando um filtro com pequenos furos colocado junto ao casco e no interior da caixa de mar, onde são geralmente colocados os filtros de sucção. A finalidade preliminar das grelhas e dos filtros é proteger o sistema de bombeamento dos objetos estranhos que estão sendo sugados pelas bombas de lastro. $\mathrm{O}$ uso adicional de telas portáteis, para impedir a entrada de organismos não desejados, tem baixa viabilidade em embarcações existentes, mas poderia ser opção atrativa se incorporado em projetos de navio novos (NATIONAL RESEARCH COUNCIL, 1996).

Uma questão importante refere-se à manutenção e fiscalização dos equipamentos de lastro do navio. O controle efetivo dos equipamentos que compõem o sistema de lastro é uma tarefa muito importante para garantir o correto funcionamento. Tubulações, válvulas e sistema de drenagem "scallops" geralmente apresentam problemas de entupimentos por areia e sedimentos que ficam retidos no fundo dos tanques. Inspeções regulares nos tanques podem indicar problemas relativos ao revestimento, estrutura e componentes do sistema de lastro que podem reduzir sua eficiência, conforme mostrado na Figura 4.

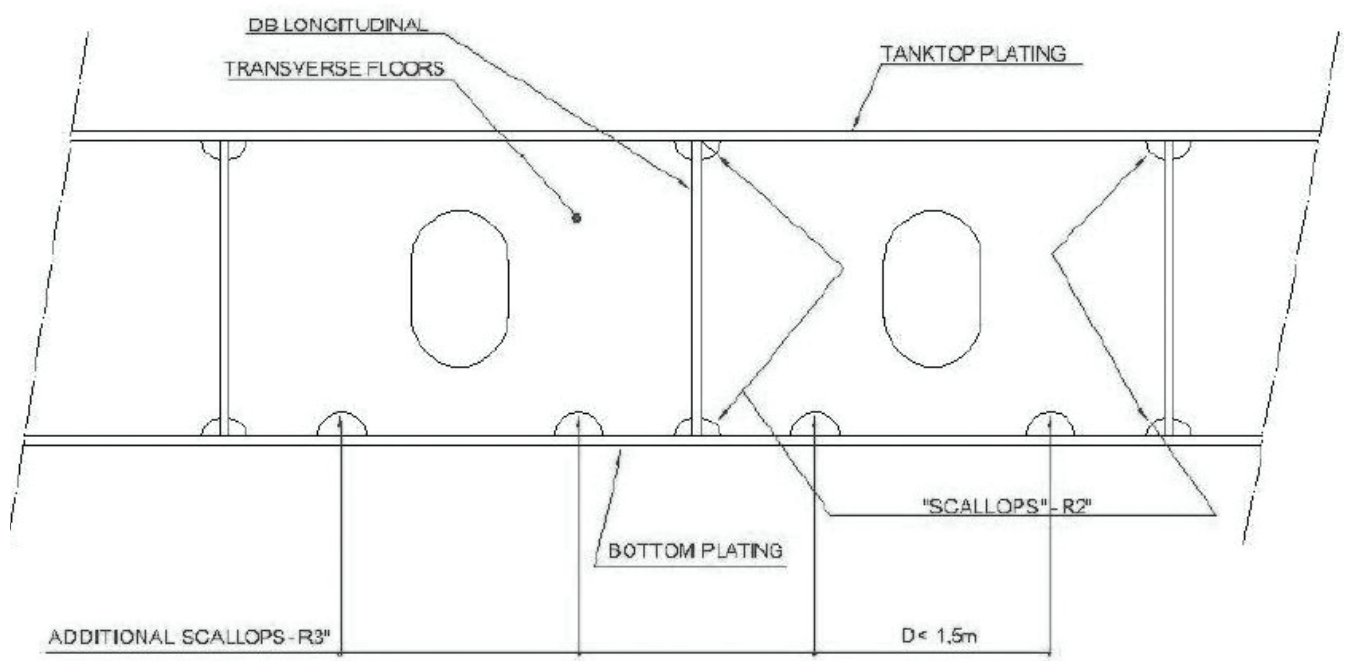

Figura 4 Sistema de drenagem no fundo do tanque utilizando-se dos "scallops"

Fonte: Prange e Pereira (2013)

O sedimento se acumula frequentemente na parte inferior e em muitas superfícies horizontais dos tanques de lastro. O sedimento pode ser lama e argila cap- 
tada em um porto. De 343 embarcações de carga que chegaram em 18 portos australianos, pelo menos $65 \%$ continham um volume significativo de sedimento na parte inferior do tanque (HALLEGRAEFF e BOLCH, 1992). O sedimento é removido tipicamente a cada três ou cinco anos quando a embarcação é submetida à docagem para inspeção.

Johengen et al. (2005) examinaram 103 navios estrangeiros que atracaram nos portos do EUA e Canadá entre 2000 e 2002 e identificaram que aproximadamente $68 \%$ deles tinham resíduos de lastro nos tanques. Aproximadamente $60 \%$ destes navios tinham $10 \mathrm{t}$ de resíduos e alguns chegavam a totalizar $200 \mathrm{t}$. Durante a visita dos autores junto à alguns navios que atracaram no porto de Santos foi possível identificar uma grande quantidade de sedimentos depositados nos fundos dos tanques de água de lastro. Praticamente, a quantidade de areia depositada alcançava altura próxima ao joelho.

Pode-se observar que, quanto maior é a capacidade de lastro do navio, maior é a quantidade residual de lastro que fica retida dentro dos tanques. Sendo assim, deve ser dada uma atenção especial para esta questão que está intimamente ligada com o processo de transferência de espécies exóticas.

Assim, para os novos navios, deve-se projetar os sistemas de captação de água do fundo dos tanques de maneira eficiente, buscando reduzir o volume residual. Johengen et al. (2005) sugere que sejam instaladas duas bombas centrifugas nos tanques, uma para retirada da maior parte da água de lastro e outra de menor capacidade rente ao fundo para retirar o lastro residual. Prange e Pereira (2013) propuseram pequenas alterações nos tanques de lastro dos navios que podem facilitar a retirada do sedimento dos tanques durante o deslatro. Basicamente, deve-se aumentar em 50\% o diâmetro das aberturas "scallops" e desenvolver um sistema de reinjeção de água no fundo dos tanques para suspender o sedimento. Iremos apresentar este estudo nas seções seguintes deste livro.

Neste contexto, deve-se considerar o desenvolvimento de algum sistema que possibilite suspender o sedimento utilizando, por exemplo, jatos d'água, para que a quantidade depositada no fundo dos tanques seja retirada junto com a água de lastro no momento do deslastro. Outra opção seria dotar o navio com um sistema coletor de sedimentos, por exemplo, um sistema de filtragem que destine os sedimentos para um tanque específico e depois separá-lo a bordo do próprio navio para ser descartado no porto.

O sedimento no fundo do tanque é um problema sério para gestão da água de lastro, pois além dos problemas de aumento de peso do navio, ele abriga muitas espécies de micro-organismos que podem ser potencialmente invasores em um novo ambiente (DRAKE et al., 2005). 


\subsection{REFERÊNCIAS}

NATIONAL RESEARCH COUNCIL (NRC) MARINE BOARD. Stemming the Tide: Controlling Introductions of Nonindigenous Species by Ships' Ballast Water. Committee on Ships' Ballast Operations, Marine Board, Commission on Engineering and Technical Systems, NRC. National Academy Press, Washington, D.C. 1996.

COHEN, A.N. Ships' Ballast Water and the Introduction of Exotic Organisms into the San 11 Francisco Estuary: Current Problem Status and Management Options. Report for California Bay 12 Delta Authority, Sacramento, CA. San Francisco Estuary Institute, Richmond, CA. 1998.

COHEN, A.N. Ships' Ballast Water and the Introduction of Exotic Organisms into the San 11 Francisco Estuary: Current Problem Status and Management Options. Report for California Bay 12 Delta Authority, Sacramento, CA. San Francisco Estuary Institute, Richmond, CA. 1998.

JOHENGEN, T. et al. A Final Report for the Project: Assessment of Transoceanic NOBOB Vessels and Low-Salinity Ballast Water as Vectors for Non-indigenous Species Introductions to the Great Lakes. National Oceanic and Atmospheric Administration, Great Lakes Environmental Research Laboratory, and University of Michigan, Cooperative Institute for Limnology and Ecosystems Research, Ann Arbor. 2005. 287 p.

BOLCH, C.J.; HALLEGRAEFF, G.M. Chemical and physical treatment options to kill toxic dinoflagellate cysts in ships' ballast water. Journal of Marine Environmental Engineering1: 1993. 23-29 p.

HALLEGRAEFF, G.M. A review of harmful algal blooms and their apparent global increase. Phycologica 32. 1993. 79-99 p.

PEREIRA N.N, PRANGE, G.J., Ship Ballast Tank Sediment Reduction Methods. Naval Engineers Journal. 2013.

DRAKE, J.M. et al. Theory and preliminary analysis of species invasions from ballast water: controlling discharge volume and location. American Midland Naturalist 154. 2005. 459-470 p. 